\title{
Amend-Traut, Anja, Wechselverbindlichkeiten vor dem Reichskammergericht. Praktiziertes Zivilrecht in der Frühen Neuzeit
}

\section{Vincent Demont}

\section{OpenEdition}

\section{Journals}

Édition électronique

URL : http://journals.openedition.org/ifha/6626

DOI : $10.4000 /$ ifha.6626

ISSN : 2198-8943

\section{Éditeur}

IFRA - Institut franco-allemand (sciences historiques et sociales)

Référence électronique

Vincent Demont, « Amend-Traut, Anja, Wechselverbindlichkeiten vor dem Reichskammergericht. Praktiziertes Zivilrecht in der Frühen Neuzeit », Revue de I'IFHA [En ligne], Date de recension, mis en ligne le 01 janvier 2011, consulté le 22 septembre 2020. URL : http://journals.openedition.org/ifha/6626 DOI : https://doi.org/10.4000/ifha.6626

Ce document a été généré automatiquement le 22 septembre 2020.

(CIFHA 


\title{
Amend-Traut, Anja, Wechselverbindlichkeiten vor dem Reichskammergericht. Praktiziertes Zivilrecht in der Frühen Neuzeit
}

\author{
Vincent Demont
}

1 Dans le droit romain, " aucune trace du droit du change » - le constat, lapidaire, est dressé en 1761 par le jurisconsulte Johann Ulrich Cramer. Le Tribunal de la Chambre impériale (Reichskammergericht) a pourtant su trancher avec méthode les litiges nés de cette " habitude de marchand ". L'institution juge avec cohérence, et cette cohérence présuppose un constant travail d'élaboration et de structuration des normes. Le présent ouvrage constitue donc d'abord un remarquable travail sur l'édification d'un nouveau pan du droit dans et par l'Empire de l'époque moderne. Pour comprendre cette construction, l'auteur choisit l'étude de cas : l'ouvrage repose sur l'analyse minutieuse des procès conservés à Francfort-sur-le-Main et portant sur des affaires de change. Du fait de l'importance de la ville dans les circuits de paiement germaniques et européens, l'échantillon est consistant, et encore augmenté par la comparaison constante avec les recueils de jurisprudence imprimée. Cette habilitation d'histoire du droit propose donc une histoire de première main, fondée sur un important travail d'archives, qui participe pleinement au basculement du quantitatif vers le qualitatif des études consacrées au Reichskammergericht.

2 Bien que l'ambition affichée soit l'étude de toute la période d'activité du tribunal (1495-1806), les sources orientent nettement et massivement vers le XVIIIe siècle : le plan est donc logiquement thématique. Après un état des lieux historiographique et une description qualitative et quantitative du corpus étudié, A.A.-T. décrit la place du Reichskammergericht dans l'univers judiciaire de l'Empire : les dispositions sur lesquels il s'appuie, les instances pour lesquelles il fait fonction de cour d'appel, et la considération dont il jouit, y sont présentées en détail. Le cœur de l'ouvrage est consacré, via une analyse des argumentaires juridiques, à l'exploration des logiques qui 
président à la production de normes juridiques par le tribunal. Ce travail montre d'abord le pragmatisme du Reichskammergericht : celui-ci peut aussi bien s'appuyer sur des usages marchands (pour la définition de l'usance, ou, avec bien plus de réticences, l'acceptation de l'endossement) que contredire ceux-ci (du fait par exemple de la permanence des interdits liés à l'usure); il fait appel aux codifications locales du change, mais aussi aux avis de prestigieuses universités de droit ou aux pratiques du commerce, souvent confirmées et officialisées par des parères. Mais la méthode choisie, et la rigueur de l'auteur, permettent d'aller bien au-delà du constat de cette souplesse, et d'une désormais classique réhabilitation de l'activité du tribunal : A.A.-T. parvient en effet à suggérer que celui-ci, au-delà du traitement concret de chaque cas, menait une véritable politique, tant dans la protection de minorités - les nombreux procès impliquant des juifs ou des femmes en sont une illustration frappante - que dans la promotion d'un espace économique.

3 Cour allemande, le Reichskammergericht traite avec le change d'une pratique européenne ; univers de juristes, il appréhende un savoir de marchands ; juridiction d'Empire, il contrôle les coutumes et instances locales. La diversité des interrogations ouvertes, et le constant souci de mise en perspective historique et historiographique manifesté par l'auteur permettent à l'ouvrage de lier perspectives d'histoire économique et sociale et évolution de l'histoire allemande des institutions. Sa densité n'est un obstacle ni à sa lecture ni à son utilisation, qu'un propos extrêmement clair, un appareil critique consistant et un triple index (onomastique, géographique et thématique) rendent aisées. Tout juste peut-on regretter certaines habitudes d'écriture, qui font qu'A.A.-T. ne date pas systématiquement les procès qu'elle utilise, ou certaines lacunes historiographiques (en particulier la méconnaissance des travaux de P. Jeannin sur Augsbourg, pour leur démonstration de l'existence d'une pratique régulière du change en Allemagne dès le XVIe siècle). Mais aucune critique ne peut faire oublier qu'A.A.-T. réussit ici un véritable tour de force : produire un livre qui porte une vraie thèse, et qui soit en même temps un vrai ouvrage de référence - en un mot, un travail marquant. 